\title{
Simple Electrochemical Determination of Surface-Active Substances in Natural Waters
}

\author{
Željka Cvrković-Karloci, ${ }^{1,2}$ Damir Krznarić, ${ }^{1}$ Marijan Šeruga, ${ }^{2}$ and Božena Ćosovićc ${ }^{1}$ \\ ${ }^{1}$ Division for Marine and Environmental Research, Rudjer Bošković Institute, Bijenička 54, 10000 Zagreb, Croatia \\ ${ }^{2}$ Faculty of Food Technology, University J.J. Strossmayer, F. Kuhača 18, 31000 Osijek, Croatia
}

Correspondence should be addressed to Božena Ćosović, cosovic@irb.hr

Received 7 March 2011; Revised 19 April 2011; Accepted 19 April 2011

Academic Editor: Sibel A. Ozkan

Copyright () 2011 Željka Cvrković-Karloci et al. This is an open access article distributed under the Creative Commons Attribution License, which permits unrestricted use, distribution, and reproduction in any medium, provided the original work is properly cited.

A simple electrochemical determination of surface-active substances by using time-dependent variation of the capacitive current in a.c. voltammetry at the HMDE is described. Surface-active substances were accumulated by stirring solution at the deposition potential of $-0.6 \mathrm{~V}$ versus $\mathrm{Ag} / \mathrm{AgCl}$ (sat. $\mathrm{NaCl}$ ). The capacitive current was recorded for different deposition times in the range $0-120 \mathrm{~s}$, wherefrom the linear calibration plot is constructed. The proposed method was verified for model surfactant TritonX-100 in the concentration range $0.02-0.25 \mathrm{mg} / \mathrm{L}$ and for humic acid in the concentration range $1.65-20 \mathrm{mg} / \mathrm{L}$. The application of the method was demonstrated for freshwater samples of the Drava river, Danube river, and the wetland Kopački Rit, Croatia. The shape of the $i_{\text {ac }}-E$ curves as well as the obtained concentrations of surface-active substances by using humic acid as the calibration substance are quite well describing the type and the nature of organic matter in the freshwater samples.

\section{Introduction}

Organic substances with surface-active properties represent a significant part of dissolved organic matter in natural aquatic systems $[1,2]$. Those substances are either naturally present or products of man's activities. The latter are very often, especially in the case of commercial tensides, less abundant in mass while on the contrary they may represent the most surface-active organic material in a particular sample [2].

Although organic surface-active substances are usually electroinactive, that is, those chemical species do not undergo electroreduction or electrooxidation within the available potential window, they can be analyzed by electrochemical methods on the basis of their influence upon the electrode double-layer structure when they get adsorbed at the electrode surface. Surface-active substances were most extensively investigated by electrochemical methods in the sea [3-7], particularly in the thin layer at the sea surface [8-10], in estuarine [11], and river water systems [12, 13], and recently in the atmospheric precipitation samples [14]. Adsorption study at the electrode-solution interface may allow quantification of surface-active substances by measuring the extent of adsorption. In the case of a mixture of adsorbable substances, the adsorption effect is expressed by using the convenient calibrating substance.

The application of the adsorption study for the analysis of organic surface-active substances has been developing in two main directions: (a) by introducing new or improvement of already existing techniques of measurement [15-17], (b) by using electrochemical method for molecular characterization of the complex mixture of naturally occurring organic adsorbable substances. The latter can be done through comparison of the electrochemical behaviour of the organic matter in the natural sample with the behaviour of the selected model substances and/or by using a complex methodological approach where different analytical techniques are combined with the electrochemical measurement $[18,19]$.

So far, a.c. voltammetry, particularly tensammetric method with adsorptive preconcentration based on recording either capacitive current or double layer capacity versus potential curves, has been most widely and successfully used for the determination of surface-active substances in aquatic systems. For quantification of the content of surface-active substances, a calibration plot of a selected standard is used, which is in fact the apparent adsorption isotherm for the selected substance at a selected accumulation time. Recently, 
a quick and simple tensammetric method was proposed that makes use of a variation in the differential capacity of double layer in relation to the time of accumulation by means of the controlled growth mercury electrode (CGME) [16]. The application of the method was illustrated on two model substances and in the determination of surface-active substances of the river water samples.

While investigating the organic matter content and the chemical composition of real natural water samples, one has to be aware of the fact that the parameters of organic matter could be changed in time and during sample treatment. Therefore, it is a great advantage if one can use simple, direct, and nondestructive analytical methods, possible in the field work and/or on board of a ship. Here, we have used a simple, portable electrochemical instrument in field measurement of surface-active substances in the river water samples. The tensammetric method of determination is modified by means of the time-dependent variation of capacitive current at the HMDE wherefrom the calibration plot was constructed.

\section{Experimental}

Surface-active substances were analyzed electrochemically by a.c. voltammetry using PalmSens portable instrument (Palm Instruments BV, Netherlands). Three electrode system was used: hanging mercury drop electrode (HMDE WK 2, Institute of Physical Chemistry, Polish Academy of Sciences, Warsaw, Poland) as a working electrode, $\mathrm{Ag} / \mathrm{AgCl}$ (sat. $\mathrm{NaCl}$ ) as the reference electrode, and platinum wire as the counter electrode. The potential of $E=-0.6 \mathrm{~V}$ was applied for accumulation of surface-active substances at different accumulation times with stirring. An applied alternating voltage of $10 \mathrm{mV}$ and the frequency of $75 \mathrm{~Hz}$ were used. The measurements were carried out in a constant-temperature room at ambient temperature $(293-+1 \mathrm{~K})$ in the cell open to air, without any sample deaeration. Freshwater samples and model substances were analyzed by addition of sat. $\mathrm{NaCl}$ to obtain $0.55 \mathrm{~mol} / \mathrm{L} \mathrm{NaCl}$ solution.

For calibration, the nonionic surfactant polyethoxyethylene-t-octylphenol (Triton-X-100) from Rohm and Haas, Milan, Italy and humic acid from Aldrich (former EGAChemie), Germany were used. This is a peat humic acid of molecular weight distribution of two pronounced peaks, one for a molecular mass of $1000 \mathrm{Da}$ and the other for $5000 \mathrm{Da}$ as reported earlier [20].

Freshwater samples were collected from the Drava river near Osijek, Croatia and the Danube river near Batina at the state border between Croatia and Hungary, as well as in the wetland of the Kopački Rit, Croatia.

Dissolved organic carbon (DOC) content of the freshwater samples was determined by using a high-temperature catalytic oxidation analyzer (TOC-5000 Model, Shimadzu, Japan).

\section{Results}

3.1. Principles of Time-Dependent Tensammetric Determination. It is well known that in a stirred solution, a layer of thickness $\delta$ (Nernst diffusion layer), in which no motion of the solution occurs, exists at the electrode. The concentration of electroactive species within this diffusion layer vary linearly with distance from the electrode [21]. Presuming a fast reaction, concentration of reactant on the electrode surface is practically zero.

In our investigations, the reactant is not a species undergoing a redox process but instead is adsorbed on the electrode. In the case of a strong adsorption and relatively short time, that is, low coverage of the electrode surface, the surface concentration of the surfactant, $\Gamma$, is defined as:

$$
\Gamma=\frac{M}{A}=\frac{D c_{0} t}{\delta},
$$

where $M$ is number of moles of surfactant, $A$ is the electrode area, $D$ diffusion coefficient, $c_{o}$ bulk concentration of surfactant, and $t$ adsorption time.

At a constant potential, differential capacity of the electrode double layer can be expressed as [22]:

$$
C_{d}=C_{\Theta=0}(1-\Theta)+C_{\Theta=1} \Theta,
$$

where $C_{\Theta=0}$ is the differential capacity of a free electrode surface, $C_{=1} \Theta$ is the differential capacity on a completely covered surface and $\Theta$ is the relative surface coverage,

$$
\Theta=\frac{\Gamma}{\Gamma_{m}},
$$

where $\Gamma_{m}$ is Surface concentration at maximal coverage.

From (2) and (3):

$$
\begin{gathered}
C_{d}=C_{\Theta=0}-\left(C_{\Theta=0}-C_{\Theta=1}\right) \frac{\Gamma}{\Gamma_{m}}, \\
C_{\mathrm{d}}=C_{\Theta=0}-K_{1} \Gamma,
\end{gathered}
$$

where $K_{1}$ is the constant since $C_{\Theta=0}, C_{\Theta=1}$, and $\Gamma_{m}$ are constants for a given surfactant.

In the tensammetric measurements, $C_{d}$ is proportional to a.c. current, $i_{\mathrm{ac}}$, and therefore:

$$
i_{\mathrm{ac}}=K_{2} C_{d}=K_{2}\left(C_{\Theta=0}-K_{1} \Gamma\right) .
$$

From (5) and (1),

$$
i_{\mathrm{ac}}=K_{2}\left(C_{\Theta=0}-K_{1} \frac{D c_{0} t}{\delta}\right) .
$$

With constant speed of solution stirring and surfactant concentration,

$$
i_{\mathrm{ac}}=K_{2} C_{\Theta=0}-K_{3} t,
$$

where

$$
K_{3}=\frac{K_{1} K_{2} D c_{0}}{\delta} .
$$

Therefore, the dependence of a.c. current, $i_{\mathrm{ac}}$, on time of deposition, $t$, is a straight line with negative slope and intercept on $i_{\mathrm{ac}}$ axis. 


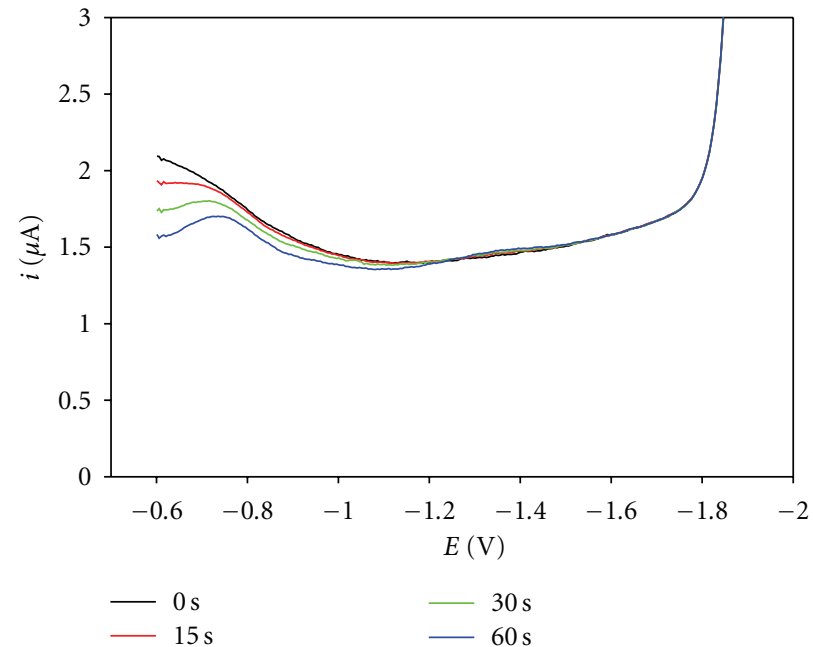

(a)

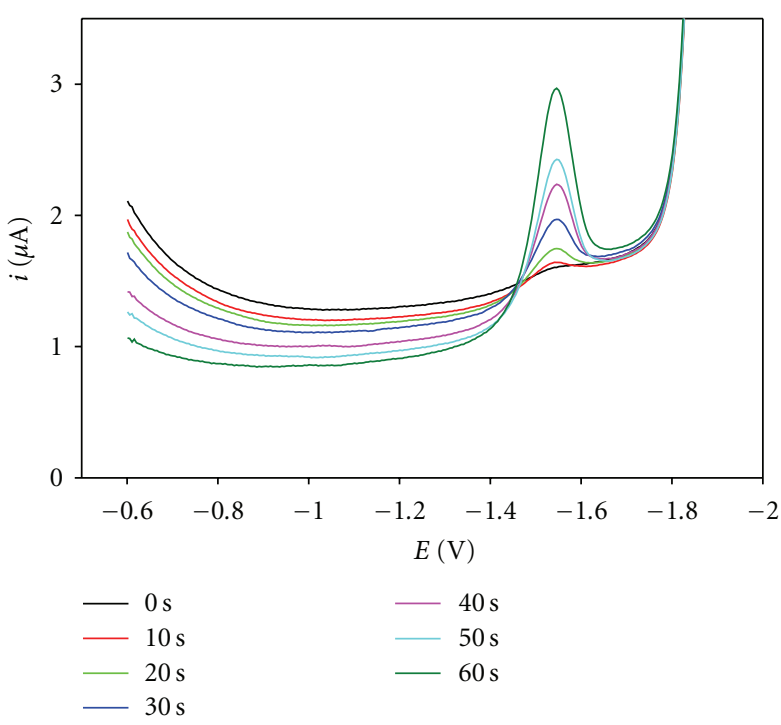

(b)

FIgure 1: $i_{\mathrm{ac}}-E$ curves for (a) humic acid, $25.85 \mathrm{mg} / \mathrm{L}$, and (b) Triton-X-100, $0.143 \mathrm{mg} / \mathrm{L}$, recorded for increasing deposition times in $0.55 \mathrm{M}$ $\mathrm{NaCl}$ solution. Deposition potential was $-0.6 \mathrm{~V}$, amplitude $10 \mathrm{mV}$, and frequency $75 \mathrm{~Hz}$.

With higher concentrations of surfactants it might be more favourable to measure under diffusion conditions. Diffusion current can be expressed by Cottrell equation [23]

$$
i_{d}=\frac{n F A D c_{0}}{\sqrt{\pi D t}} .
$$

In order to develop the equation for the dependence of a.c. current on surfactant concentration, we start with (9) and proceed in the same manner as above. The final dependence of a.c. current on time is

$$
i_{\mathrm{ac}}=K_{2} C_{\Theta=0}-K_{3} \sqrt{t}
$$

where

$$
K_{3}=K_{1} K_{2} \frac{c_{0} \sqrt{D}}{\sqrt{\pi}} .
$$

Thus, under diffusion conditions, current is proportional to the square root of time of deposition.

\subsection{Application of the Method: Model Substances and Natural} Samples. In order to test our experimental conditions, two model surfactants were used, T-X-100 and humic acid. In Figures 1(a) and 1(b), the dependence of a.c. current on potential for the two surfactants are given. At the potential of $-0.6 \mathrm{~V}$, which is close to the potential of electrocapillary zero, both surfactants are strongly adsorbed. Decrease of $i_{\text {ac }}$ with $t$ was measured by registering $i_{\mathrm{ac}}$ at $0,15,30$, and $60 \mathrm{~s}$ of deposition, each time on a fresh $\mathrm{Hg}$ drop, and with stirring of solution. A series of straight lines was obtained for T-X-100 and humic acid (Figures 2(a) and 2(b)) as expected from (7). It would have been more appropriate to measure continuously the change of current with time for
TABLE 1: Determination of surface-active substances in freshwater samples by electrochemical method. Concentrations are expressed in equivalent amounts of two different standards (Triton-X-100 and humic acid). Concentrations of dissolved organic carbon (DOC) in the samples are given too. Samples were collected and analyzed on March 3, 2006.

\begin{tabular}{lccc}
\hline Freshwater samples & $\begin{array}{c}\text { DOC } \\
\text { mg C/L }\end{array}$ & $\begin{array}{c}\text { SAS } \\
\text { eqiuv. T-X-100, } \\
\text { mg/L }\end{array}$ & $\begin{array}{c}\text { SAS } \\
\text { equiv. Humic } \\
\text { a., mg/L }\end{array}$ \\
\hline Drava River, Osijek & 4.91 & 0.067 & 15.97 \\
Danube River, Batina & 4.21 & 0.079 & 18.78 \\
Kopački Rit, Wetland & 10.13 & 0.077 & 18.47 \\
\hline
\end{tabular}

each concentration, but, unfortunately, the instrument used for the field measurements had no such possibilities.

Since field measurements are often done in a span of several days or even months and with different HMDE, the electrode surface areas could vary somewhat. In order to minimize such errors, the lines in Figure 2 were plotted as relative currents by dividing all values with the intercept of the line for supporting electrolyte, which was $0.55 \mathrm{~mol} \mathrm{~L}^{-1}$ $\mathrm{NaCl}$ (Figures 3(a) and 3(b)). Supporting electrolyte was recorded before every set of measurements.

For each surfactant, the relative slope $K_{3}$ of $i_{\mathrm{ac}}-t$ lines was plotted against bulk concentration of the surfactant. Good, straight lines, with intercept equal to zero, were obtained in both cases (Figures 4(a) and 4(b)). The concentrations of the mixture of the unknown surfactants from natural waters were always measured using these two calibration lines, that is, they were reported as equivalent to a certain concentration of T-X-100 and humic acid. 


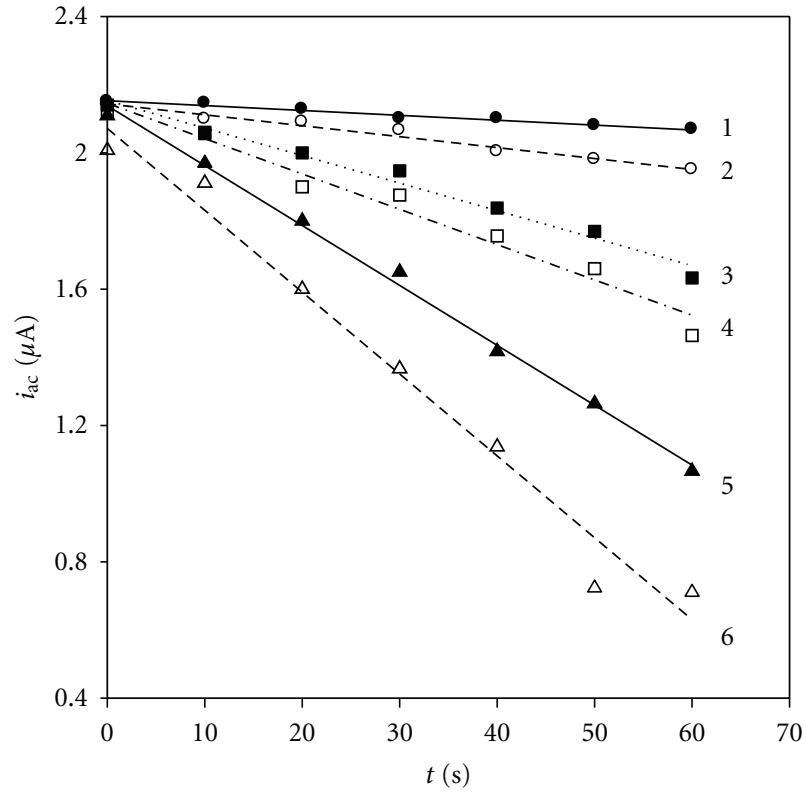

(a)

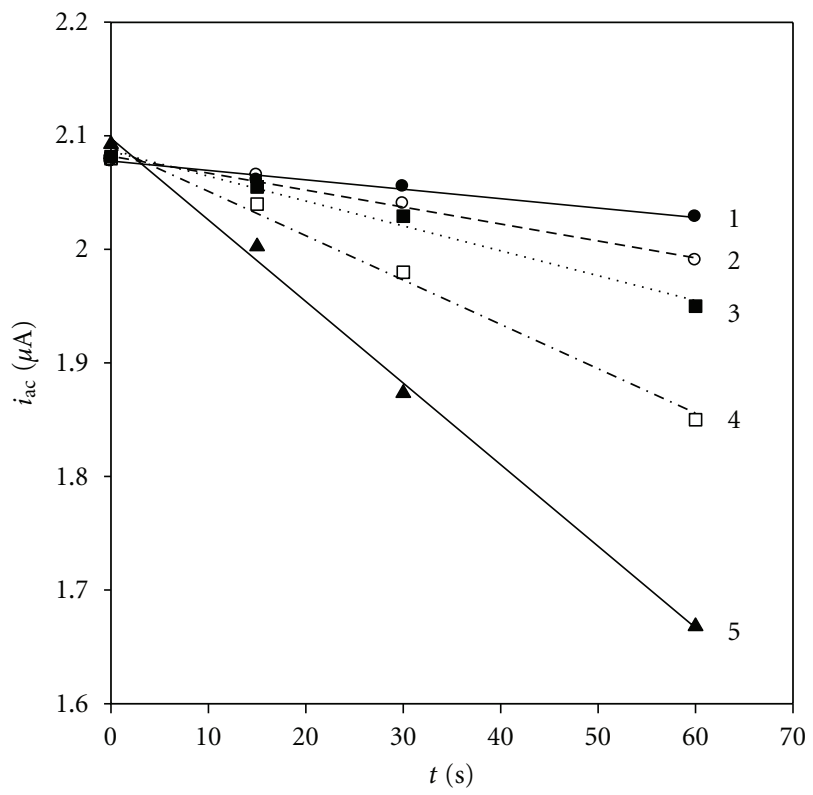

(b)

FIGURE 2: $i_{\mathrm{ac}}-t$ curves for different concentrations of (a) T-X-100: (1) $0 \mathrm{mgL}^{-1}$, (2) $0.0237 \mathrm{mgL}^{-1}$, (3) $0.0594 \mathrm{mgL}^{-1}$, (4) $0.0951 \mathrm{mgL}^{-1}$, (5) $0.143 \mathrm{mgL}^{-1}$, and (6) $0.190 \mathrm{mgL}^{-1}$ and (b) humic acid: (1) $1.65 \mathrm{mgL}^{-1}$, (2) $4.4 \mathrm{mgL}^{-1}$, (3) $6.6 \mathrm{mgL}^{-1}$, (4) $10.45 \mathrm{mgL}^{-1}$, and (5) $16.5 \mathrm{mgL}^{-1}$. Supporting electrolyte: $0.55 \mathrm{M} \mathrm{NaCl}$. Peak-to-peak amplitude $10 \mathrm{mV}$, frequency $75 \mathrm{~Hz}$. Each point represents a freshly formed $\mathrm{Hg}$ drop.

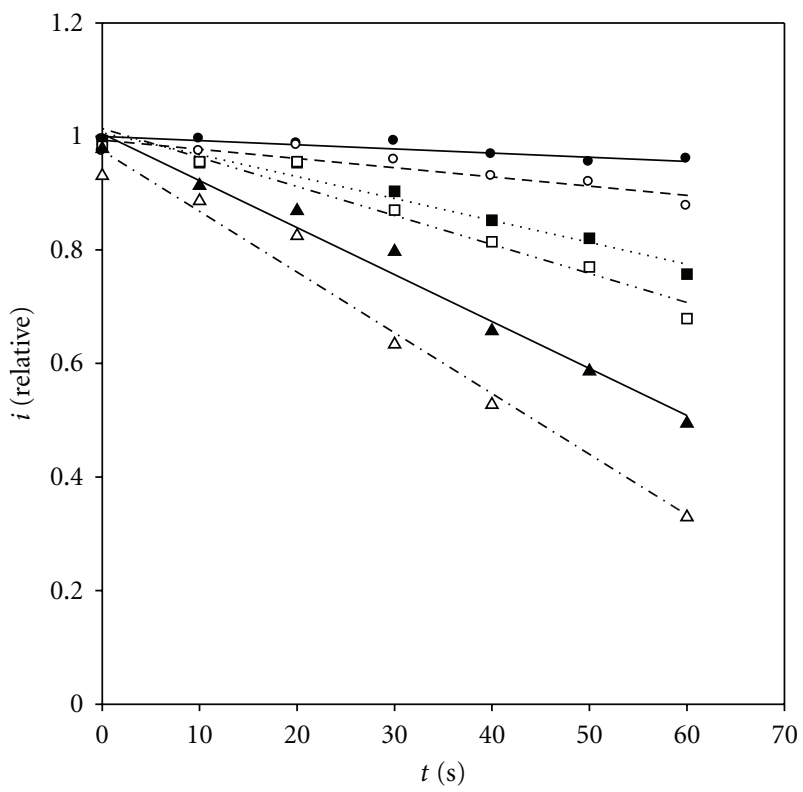

(a)

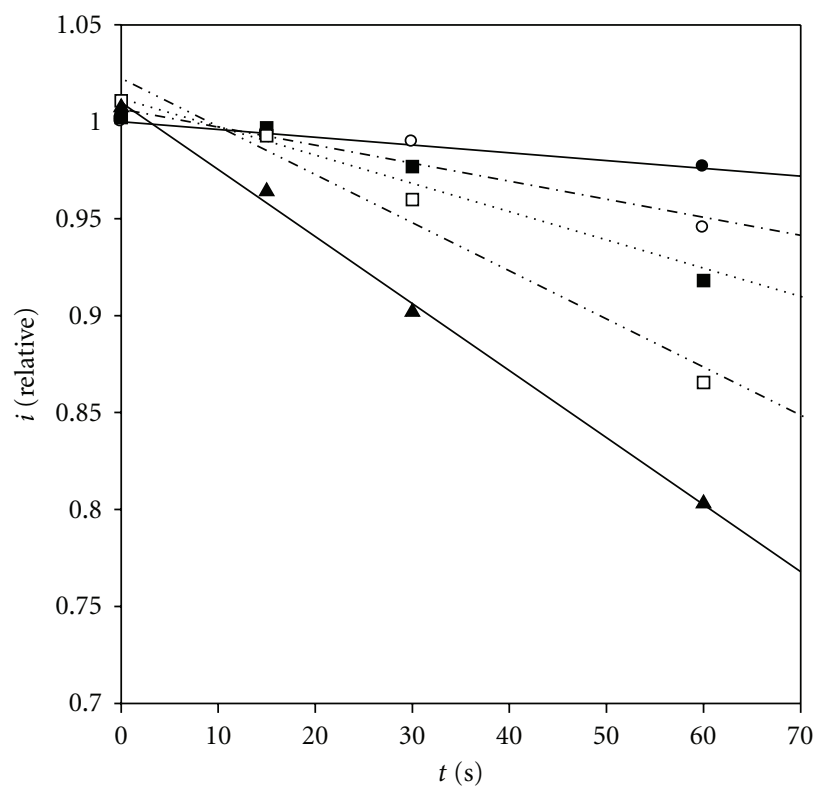

(b)

FIgURE 3: $i_{\mathrm{ac}}$ (relative)- $t$ curves obtained by dividing the results in Figure 2 by the value for supporting electrolyte at $t=0 \mathrm{~s}$.

The linear calibration plot represents an improvement of the tensammetric method in comparison with the use of the calibration plot which is the apparent adsorption isotherm for a selected model surfactant at one selected adsorption time. The calibration plot obtained at one selected accumulation time can be used only in a narrow concentration range, that is, below surface saturation $[5,24]$. When surface-active substances are determined in different aquatic samples, sometimes they need to be measured at different accumulation times in order to extend the concentration range. In comparison to the use of several adsorption isotherms, each for the selected accumulation 


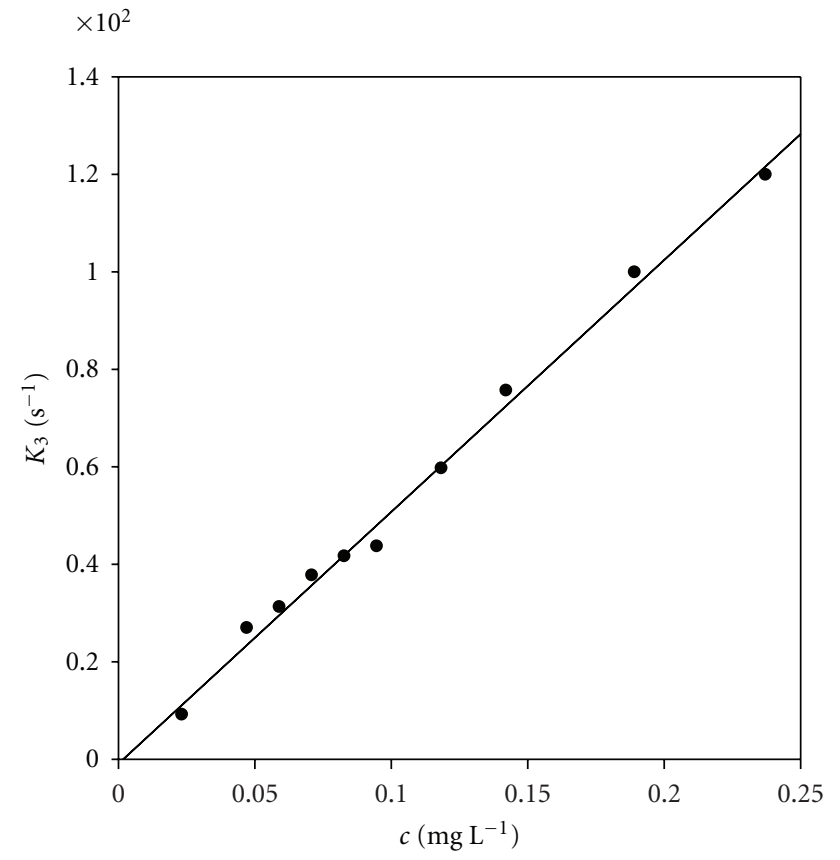

(a)

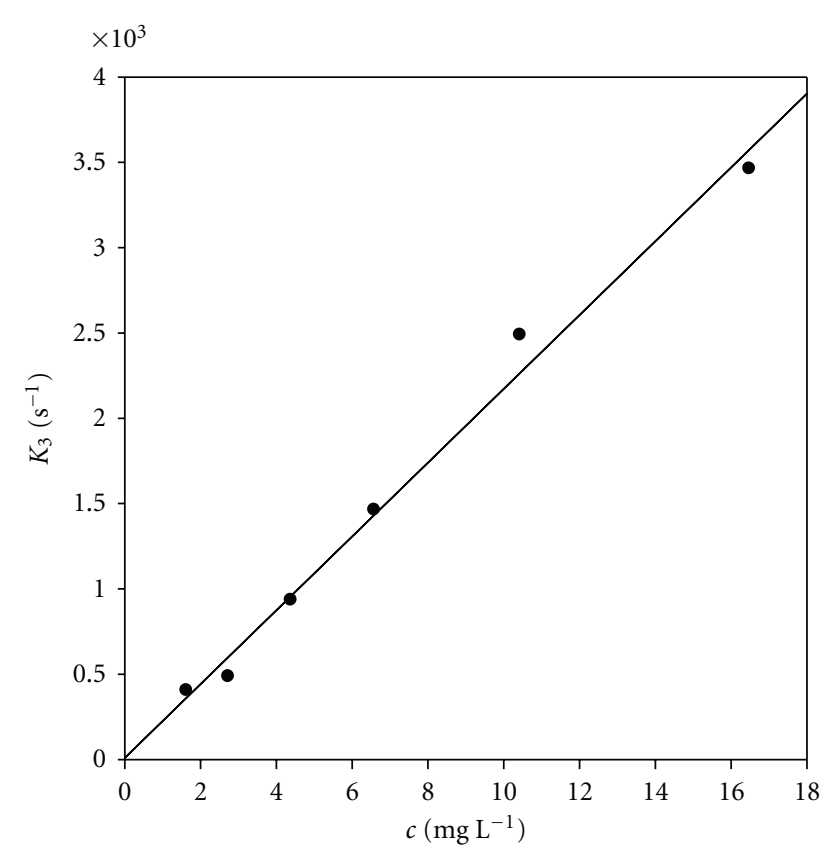

(b)

Figure 4: The calibration curves for (a) T-X-100 and (b) humic acid constructed by plotting the slopes from $i_{\mathrm{ac}}$ (relative)- $t$ lines against concentrations. All conditions as in Figures 2 and 3.

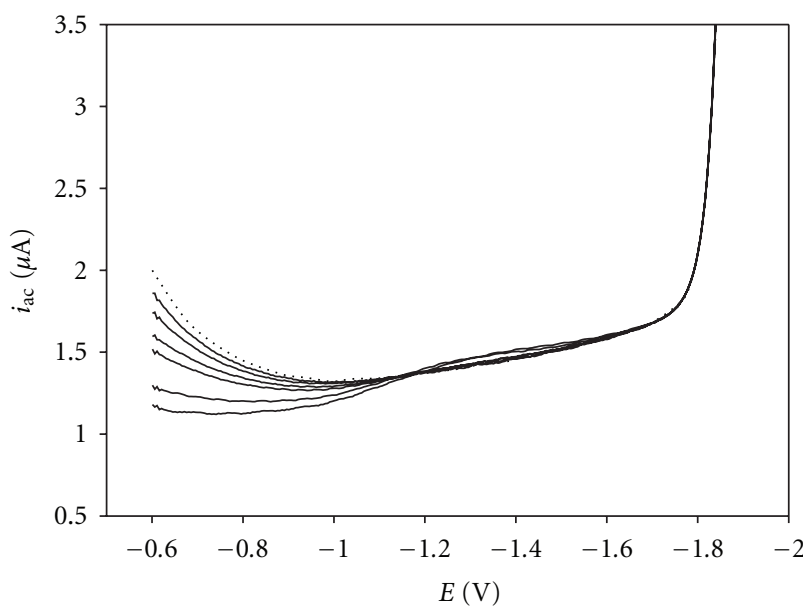

FIgURE 5: $i_{\text {ac }}-E$ curves for a sample of Drava river with increasing deposition times from $0 \mathrm{~s}$ (dotted line) to $120 \mathrm{~s}$. Deposition potential was $-0.6 \mathrm{~V}$, amplitude $10 \mathrm{mV}$, frequency $75 \mathrm{~Hz}$. $0.55 \mathrm{M}$ $\mathrm{NaCl}$ was added to the sample.

time, the advantage of the proposed method is based on the fact that in the time-dependent variation of the capacitive current, all data for different accumulation times are used in one plot, and the concentration of surface-active substances is determined from the linear calibration plot.

The application of the method for the surfactant analysis in a natural water sample is illustrated in Figures 5 and 6.

In Figure 5 are given $i_{\mathrm{ac}}-E$ curves for a sample of Drava river in Croatia. Deposition was done at $-0.6 \mathrm{~V}$ with stirring

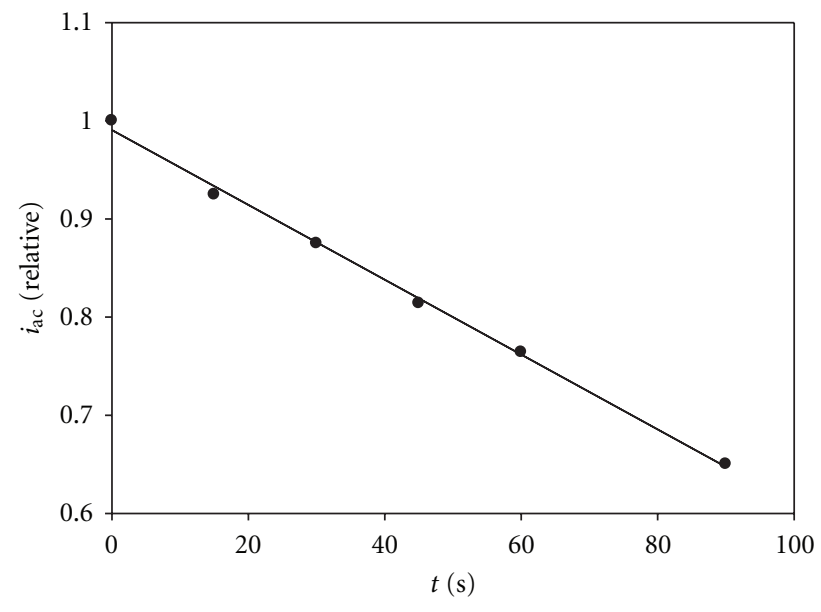

Figure 6: $i_{\text {ac }}$ (relative)- $t$ curve constructed from the results in Figure 5. $i_{\mathrm{ac}}$ current was recorded at $-0.6 \mathrm{~V}$. The slope was calculated from the first 5 points on the curve.

of solution. From the shape of the curves, it follows that the surfactants present in that sample behave more like humic acid than T-X-100. No well-defined desorption peaks at negative potentials were observed as in the case of T-X-100. Instead, a low and extended hump around $-1.2 \mathrm{~V}$ to $-1.6 \mathrm{~V}$ suggests a partial desorption of segments in the surfactant molecule similar to humic acid. The relative currents at $-0.6 \mathrm{~V}$ were plotted against deposition time. A good straight line was obtained whose slope was $3.83 \times 10^{-3} \mathrm{~s}^{-1}$ (Figure 6). 
It was well within the range of both calibration curves in Figure 4. The concentration of unknown surfactant in the sample corresponds to $0.0759 \mathrm{mg} \mathrm{L}^{-1} \mathrm{TX}-100$ or $17.66 \mathrm{mg}$ $\mathrm{L}^{-1}$ humic acid.

In Table 1 are presented data for surface-active substances of three freshwater systems as determined by the described electrochemical method. For comparison, the concentrations of dissolved organic carbon for the same samples are given too. As shown, the concentrations of organic matter are relatively high, 4.91 and $4.21 \mathrm{mg} \mathrm{C} / \mathrm{L}$ for river water samples and $10.13 \mathrm{mg} \mathrm{C} / \mathrm{L}$ for the wetland sample.

Neither of the calibration substances used, TritonX-100 or humic acid, can completely describe the composition and behaviour of naturally occurring organic surface-active substances in the investigated samples. It is important to mention that $K_{3}$ values in the (8), which are linearly proportional to the concentration of surfactant, at the same time depend on the characteristics of the adsorbed surfaceactive substances, both the naturally occurring and the calibration substances. Those characteristics are the diffusion coefficients, as well as the adsorption parameters, $\Gamma_{m}$ and the differential capacities, which are included in the constant $K_{1}$.

The relative standard deviation obtained for multiple analyses of the same solution containing surfactant such that TX-100 at the level $100 \mu \mathrm{g} \mathrm{L} \mathrm{L}^{-1}$ was $5 \%$, which is fairly good. When concentrations of the mixture of the unknown surfactants from natural waters are measured, the choice of the calibration substance is relevant as mentioned in our previous papers $[5,24]$.

The advantage of TritonX-100 is that because it is widely used as standard, it allows comparison of different natural water samples. For example, the concentrations of surfaceactive substances, expressed in equivalent of TritonX-100, for samples in Table 1 are relatively low, as compared with other freshwater systems as determined by a.c. voltammetry $[12,13,25]$ in spite of the fact that the concentrations of dissolved organic matter, in particular freshwater samples are high (Table 1).

If we compare the shape of the a.c. voltammetric curves of natural freshwater samples with those of model substances, it becomes clear that natural samples fit better to the humic-type substances. Taking into account the elemental composition of humic substances (corresponding to about $50 \%$ of organic carbon), it comes out that the concentration of surface-active substances of natural freshwater samples, when expressed in equivalents of humic substance, reveal quite well the chemical nature and behaviour of naturally occurring organic matter in the investigated samples. These are in accordance with our previous investigation of freshwater systems [12].

\section{Acknowledgments}

Financial support of the Ministry of Science, Education, and Sports of Republic of Croatia for the project "Nature of organic matter, interaction with traces and surfaces in environment" is gratefully acknowledged.

\section{References}

[1] K. A. Hunter and P. S. Liss, "Polarographic measurement of surface-active material in natural waters," Water Research, vol. 15, no. 2, pp. 203-215, 1981.

[2] B. Ćosović, "Aqueous surface chemistry. Adsorption characteristics of organic solutes. Electrochemical evaluation," in Chemical Processes in Lakes, W. Stumm, Ed., pp. 55-80, Wiley, New York, NY, USA, 1985.

[3] B. Ćosović and V. Vojvodić, "The application of a.c. polarography to the determination of surface active substances in seawater," Limnology and Oceanography, vol. 27, pp. 361-369, 1982.

[4] B. Ćosović and I. Ciglenećki, "Surface active substances in the Eastern Mediterranean," Croatica Chemica Acta, vol. 70, no. 1, pp. 361-371, 1997.

[5] B. Ćosović and V. Vojvodić, "Voltammetric analysis of surface active substances in natural seawater," Electroanalysis, vol. 10, no. 6, pp. 429-434, 1998.

[6] B. Gašparović and B. Ćosović, "Distribution of surface-active substances in the northern Adriatic Sea," Marine Chemistry, vol. 75, no. 4, pp. 301-313, 2001.

[7] B. Gašparović, M. Plavšić, N. Bošković, B. Ćosović, and M. Reigstad, "Organic matter characterization in Barents Sea and eastern Arctic Ocean during summer," Marine Chemistry, vol. 105, no. 1-2, pp. 151-165, 2007.

[8] B. Ćosović, V. Zutić, V. Vojvodic, and T. Pleše, "Determination of surfactant activity and anionic detergents in seawater and surface microlayer in the Mediterranean," Marine Chemistry, vol. 17, no. 2, pp. 127-139, 1985.

[9] B. Gašparović, M. Plavšić, B. Ćosović, and A. Saliot, "Organic matter characterization in the sea surface microlayers in the subarctic Norwegian fjords region," Marine Chemistry, vol. 105, no. 1-2, pp. 1-14, 2007.

[10] S. Frka, Z. Kozarac, and B. Ćosović, "Characterization and seasonal variations of surface active substances in the natural sea surface micro-layers of the coastal Middle Adriatic stations," Estuarine, Coastal and Shelf Science, vol. 85, no. 4, pp. 555-564, 2009.

[11] V. Vojvodić and B. Ćosović, "The hydrophobic fraction of organic matter in the Krka River estuary," Marine Chemistry, vol. 39, no. 4, pp. 251-267, 1992.

[12] B. Ćosović, V. Vojvodić, and T. Pleše, "Electrochemical determination and characterization of surface active substances in freshwaters," Water Research, vol. 19, no. 2, pp. 175-183, 1985.

[13] E. Bednarkiewicz, M. Donten, and Z. Kublik, "Determination of traces of surfactants in distilled, potable and untreated waters and in supporting electrolytes by tensammetry with accumulation on the HMDE," Journal of Electroanalytical Chemistry, vol. 127, pp. 241-253, 1981.

[14] B. Ćosović, P. O. Leko, and Z. Kozarac, "Rainwater dissolved organic carbon: characterization of surface active substances by electrochemical method," Electroanalysis, vol. 19, no. 19-20, pp. 2077-2084, 2007.

[15] D. Krznarić, T. Goričnik, and B. Ćosović, "Electrochemical determination of organic surface active substances in model and natural sea water with $\mathrm{Au}(\mathrm{III})$ monocrystal electrode," Croatica Chemica Acta, vol. 73, no. 1, pp. 247-261, 2000.

[16] B. Baś and M. Jakubowska, "Estimation of non-ionic, surfaceactive substances in aqueous solutions by means of the Controlled Growth Mercury Electrode," Analytica Chimica Acta, vol. 592, no. 2, pp. 218-225, 2007.

[17] J. Morchalo, R. Rydlichowski, A. Szymanski, B. Wyrwas, and Z. Lukaszewski, "PTFE capillary trap as a tool to monitor 
non-ionic surfactants in the aquatic environment," Analytica Chimica Acta, vol. 540, no. 1, pp. 9-15, 2005.

[18] V. Vojvodić and B. Ćosović, "Fractionation of surface active substances on the XAD-8 resin: Adriatic Sea samples and phytoplankton culture media," Marine Chemistry, vol. 54, no. 1-2, pp. 119-133, 1996.

[19] Z. Kozarac, B. Ćosović, S. Frka, D. Möbius, and S. Hacke, "Complex methodological approach to the studies of natural microlayers at the air/water interface," Colloids and Surfaces A, vol. 219, pp. 173-186, 2003.

[20] M. Ochs, B. Ćosović, and W. Stumm, "Coordinative and hydrophobic interaction of humic substances with hydrophilic $\mathrm{Al}_{2} \mathrm{O}_{3}$ and hydrophobic mercury surfaces," Geochimica et Cosmochimica Acta, vol. 58, no. 2, pp. 639-650, 1994.

[21] W. Davison, "Defining the electroanalytically measured species in a natural water sample," Journal of Electroanalytical Chemistry, vol. 87, no. 3, pp. 395-404, 1978.

[22] B. B. Damaskin, O. A. Petrii, and V. V. Batrakov, Adsorption of Organic Compounds on Electrodes, Plenum Press, New York, NY, USA, 1971.

[23] R. G. Compton and C. E. Banks, Understanding Voltammetry, World Scientific, Singapore, 2007.

[24] B. Ćosović and V. Vojvodic, "Direct determination of surface active substances in natural waters," Marine Chemistry, vol. 22, pp. 363-373, 1987.

[25] B. Ćosović, D. Hršak, V. Vojvodić, and D. Krznarić, “Transformation of organic matter and bank filtration from a polluted stream," Water Research, vol. 30, no. 12, pp. 2921-2928, 1996. 


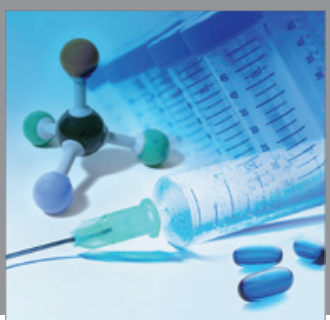

International Journal of

Medicinal Chemistry

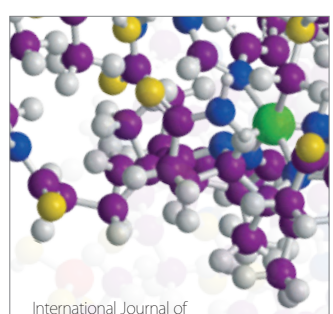

Carbohydrate Chemistry

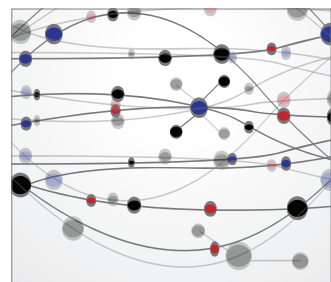

The Scientific World Journal
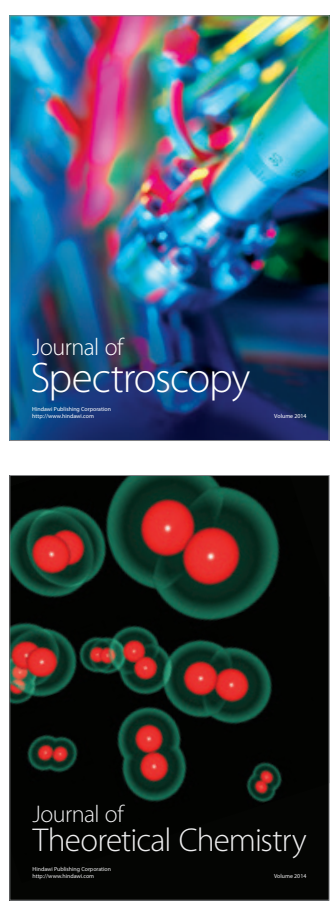
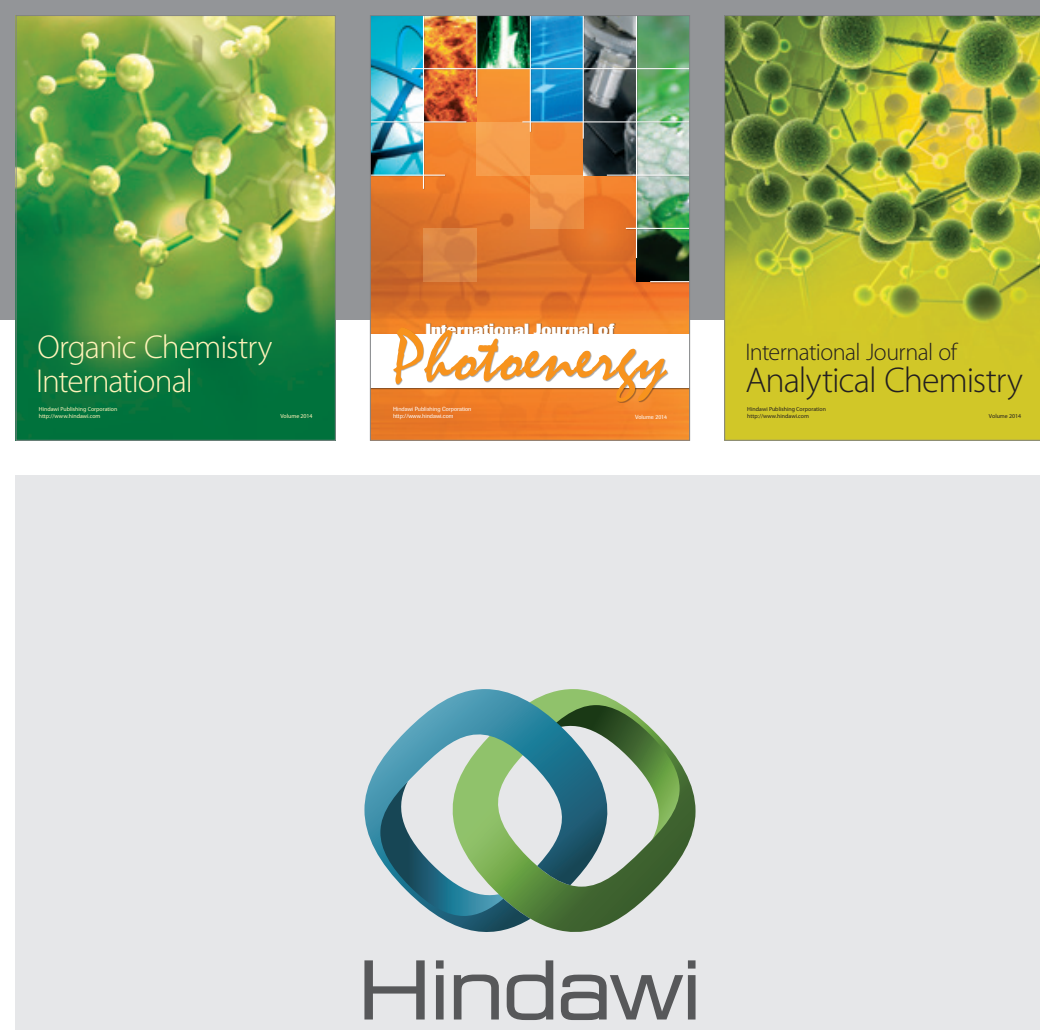

Submit your manuscripts at

http://www.hindawi.com
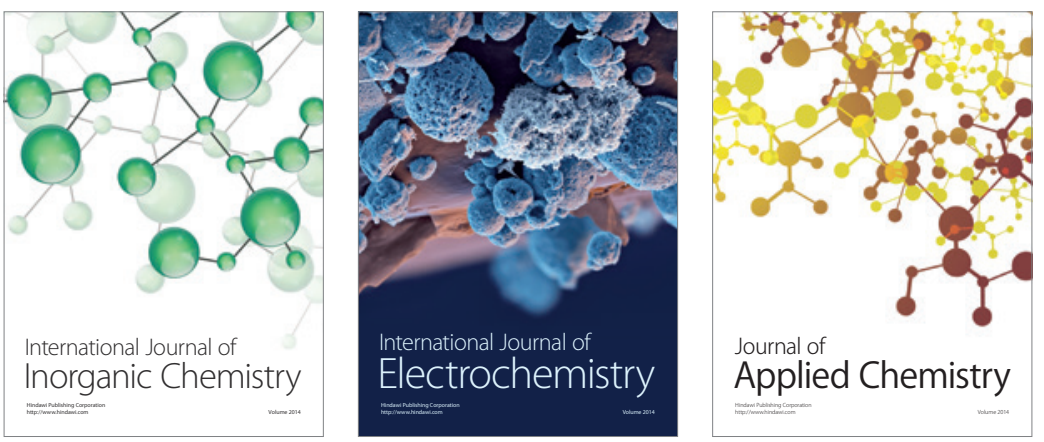

Journal of

Applied Chemistry
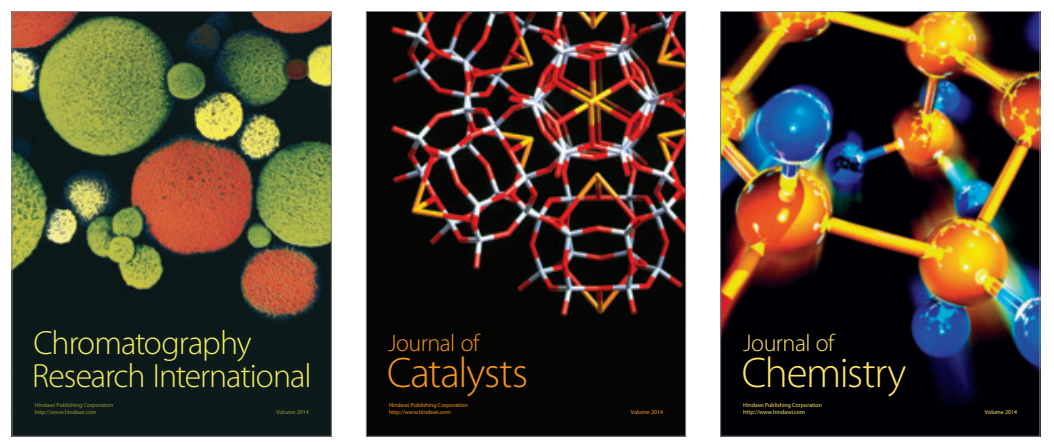
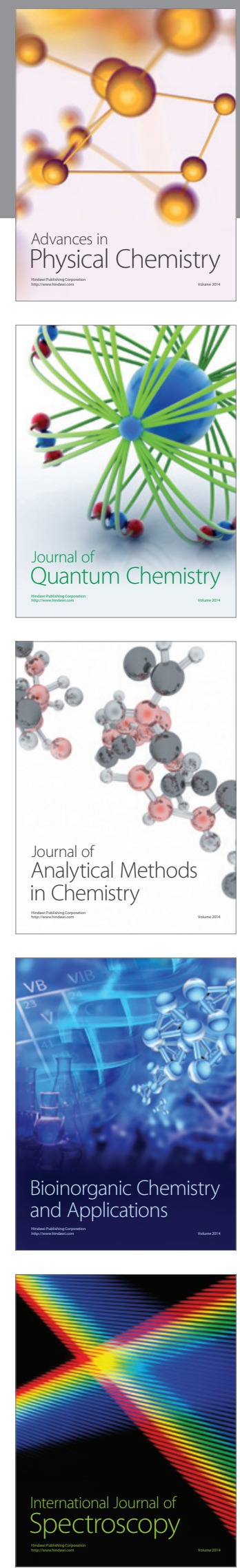